\title{
OUTCOME OF ANASTOMOTIC URETHROPLASTY IN POSTERIOR URETHRAL DISTRACTION DEFECT WITH OR WITHOUT MUCOSAL FIXATION-A RANDOMIZED CLINICAL TRIAL
}

\author{
SAYEM HOSSAIN ${ }^{1}$, AKM KHURSHIDUL ALAM ${ }^{1}$, HASINA SADIA KHAN ${ }^{1}$, MOHAMMAD SALAHUDDIN \\ FARUQUE ${ }^{1}$, ISMAT JAHAN ${ }^{2}$, ASM SHAFIUL AZAM ${ }^{1}$
}

${ }^{1}$ Department of Urology, Bangabandhu Sheikh Mujib Medical University, Dhaka, ${ }^{2}$ Department of Neonatology, Bangabandhu Sheikh Mujib Medical University, Dhaka .

\begin{abstract}
Introduction: Anastomotic urethroplasty is the treatment of choice for posterior urethral distraction defect. To notice the high failure rate of anastomotic urethroplasty, several peri-operative factors are identified. Among the per-operative factors, mucosal fixation of the both urethral ends is one of the outcome influencing factor that is recently identified. So, this randomized clinical trial has been designed to compare the outcome of anastomotic urethroplasty in posterior urethral distraction defects with or without mucosal fixation.
\end{abstract}

Objective: To compare the outcome of anastomotic urethroplasty of PUDD patient groups with or without mucosal fixation in terms of post-operative IPSS, maximum urine flow rate and post void residual urine.

Patients and Methods: The present study was conducted in the department of Urology, BSMMU between January'16 - November'17. Posterior urethral distraction defects with length of gap between two urethral segments upto $3 \mathrm{~cm}$. were included in the study. The patients in whom anastomotic urethroplasty were done with mucosal fixation were enrolled as study group $(n=21)$ and patients in whom anastomotic urethroplasty were done without mucosal fixation were included as control group $(n=21)$. All the patients were followed upto 6 months of anstomotic urethroplasty and failure of anastomotic urethroplasty (by RGU and $M C U), P V R$ and maximum urine flow rate (Qmax) in between two groups were compared.

Result: The failure rate was found significantly higher in control group than in the study group ( $p=0.043)$. The control group showed highly significant $(0.001)$ increase in postoperative PVR than the study group and the study group showed significant (0.007) increase in post operative maximum urine flow rate than the control group as was assumed in the hypothesis.

Conclusion: In conclusion, it can be said that anastomotic urethroplasty with mucosal fixation is a better option than anstomotic urethroplasty without mucosal fixation. But multicentric trial is needed to further comment.

Keywords: Posterior urethral distraction defect, anastomotic urethroplasty, mucosal fixation, failure.

Bangladesh J. Urol. 2018; 21(1):31-34

\section{Introduction}

Posterior urethral stricture is an obliterative process in the posterior urethra that has resulted in fibrosis and is generally the effect of distraction in the area caused by either trauma or radical prostatectomy. Posterior urethral

Correspondences: Sayem Hossain, Department of Urology, Bangabandhu Sheikh Mujib Medical University, Dhaka, "strictures" are not included in the common definition of urethral stricture. Distraction defects are process of the membranous urethra associated with pelvic fracture. Other narrowing of the posterior urethra are termed urethral contractures or stenosis ${ }^{1}$.

Posterior urethral distraction defects (PUDD) are almost always associated with pelvic fractures. In fact, $10 \%$ of 
pelvic fractures result in posterior urethral distraction defects: approximately $90 \%$ of such injuries are caused by motor vehicle accidents and the remainder by falls, crush injuries and gun shots ${ }^{2}$.

In general, injuries to the membranous urethra after pelvic fracture may be categorized as urethral elongation injuries, partial urethral disruption or complete urethral disruptions. In approximately one third of all urethral injuries after pelvic fracture the urethra is only partially torn and is usually heal without stricture or with only short stricture that may be manageable by either dilatation or direct vision internal urethrotomy?

On the other hand, when the urethral continuity due to pelvic fracture is totally destructed, the term posterior urethral distraction defect is used ${ }^{3}$. Now a day's, posterior urethral distraction defect is named as pelvic fracture urethral injuries ${ }^{1}$.

Urethral disruption is confirmed by antegrade and retrograde cystourethrogram and MRI (Magnetic resonance imaging) is used to detect prostatic displacement and extent of scar tissue between two urethral segments ${ }^{1}$. Webster described different treatment options for posterior urethral distraction defects(PUDD), these were- immediate urethral realignment, delayed primary repair (usually within first 10 days) and delayed surgical repair (anastomotic urethroplasty) $)^{2}$.

Considering the high failure rate of immediate urethral realignment and delayed primary repair, anastomotic urethroplasty is the treatment of choice for posterior urethral distraction defect. The desired timetable for urethral reconstruction is within 4-6 months after the trauma. As at 3 months, scar tissue at the urethral disruption site is stable enough to allow posterior urethroplasty to be undertaken safely, provided that associated injuries are stabilized and the patient is ambulatory ${ }^{1}$.

End-to-end anastomosis is the mostly performed technique. The reconstructive approach may be perineal, transpubic and abdomino-perineal. Among them most of the injuries are amenable to perineal approach ${ }^{3}$.

The success rate of anastomotic urethroplasty varies from $63 \%$ to $85 \% 4$. Several factors are identified as factors affecting outcome. These factors may be timing of surgery, surgical approaches, lateral displacement of the prostate and certain per-operative factors- excision of scar tissue, lateral fixation of mucosa of the two urethral ends, suture size and number of sutures. A recent study showed that only fixation of the mucosa of the two urethral ends improves the success rate of anastomotic urethroplasty from $67 \%-92 \%{ }^{5}$, as the fixtion of mucosa to the surrounding corpus spongiosum or to the periurethral prostatic tissue ensure the mucosa to mucosal apposition and that inhibit fibrosis or stenosis at the anastomotic site.

So, the present study was designed to compare the outcome of anastomotic urethroplasty with or without mucosal fixation.

\section{Materials and Method}

This randomized clinical trial was conducted in department of Urology, BSMMU beyween January'16November'17. The patients with posterior urethral distraction defect visited to Urology out patient department of Bangabandhu Sheikh Mujib Medical University from January'2016 to October'2017. All male patients between $18-55$ years were included in the study. More than $3 \mathrm{~cm}$ gap between the two urethral ends on RGU and MCU were excluded from the study. No patients having urethro-cutaneous fistula, urethral strictures other than PUDD, recurrent stricture after failed anastomotic urethroplasty or neurogenic bladder were included in the study. The procedures of anastomotic urethroplasty with or without urethral mucosal fixation was explained to the patient. Then the procedure of urethroplasty was selected for the patient by lottery.

Study group $(n=21)$ underwent anastomotic urethroplasty with urethral mucosal fixation to the corpus spongiosum or periurethral prostatic tissue and control group $(n=21)$ underwent anastomotic urethroplasty without mucosal fixation in traditional way. To achieve urethral mucosato-mucosal aposition, fixation of urethral mucosa with corpus spongeosum in the distal part and periurethral prostatic tissue was done in 4 to 6 sites with 4-0 polyglactin after spatulation in study group. Mucosal fixation was not done in control group.

All the patients were followed upto 6 months after anastomotic urethroplasty (upto November'17) and recurrence of stricture (by RGU and $M C U$ ), post void residual urine (PVR) and maximum urine flow rate ( $Q$ max) in between two groups were compared. Chi-squared test was performed for qualitative variable and for quantitative variable students T-test was performed. SPSS version 20 was used for statistical analysis.

\section{Result}

The patients included in the study were in the age range of 18-55 years. Most of the patients in study group were in $35-45$ years age group $(47.62 \%)$ and in control group 
the majority were in the age group of $45-55$ years $(38.1 \%)$. Mean $( \pm S D)$ age of study group was $37.00( \pm 7.668)$ years and control group was $38.76( \pm 8.526)$ years. Difference between age of two groups were not statistically significant $(p=0.379)$.

The mean $( \pm S D)$ length of gap of study group was $2.338( \pm 0.417) \mathrm{cm}$. and control group was $2.690( \pm 0.308)$ $\mathrm{cm}$. The mean $( \pm S D)$ duration passed after urethral injury of study group was $10.00( \pm 2.324)$ months and control group was $10.38( \pm 2.729)$ months. So, both the study and control groups were statistically similar in terms of length of gap $(p=0.135)$ and duration passed after urethral injury $(p=0.332)$.

The total failure was $12(28.57 \%)$.It was noted significantly ( $p=0.043)$ higher in control group 9(42.29\%) than in study group 3(14.29\%). (Table-I).

\section{Table-I}

\begin{tabular}{cccc}
\hline & Study group & Control group & P-value \\
\hline $\mathrm{N}(\%)$ & $\mathrm{N}(\%)$ & \\
Failure & $3(14.29 \%)$ & $9(42.29 \%)$ & 0.043 \\
\hline
\end{tabular}

The mean $( \pm S D)$ post-operative IPSS of study group was $6.762( \pm 7.15)$ and control group was $14.00( \pm 9.84)$.So, the control group showed a highly significant $(p=0.003)$ increase in IPSS score in post-operative period than in the study group. The postoperative PVR is increased in the control group. The mean increase in post operative PVR is noted higher in the control group than in study group. And the amount of increase is statistically highly significant $(p=0.001)$. The mean increase in maximum urine flow rate (Qmax) after anastmotic urethroplasty in study group $(15.467 \pm 4.5665 \mathrm{ml} / \mathrm{s})$ is noted significantly higher $(p=0.007)$ than in control group $(13.871 \pm 6.6735$ $\mathrm{ml} / \mathrm{s})$. (Table - II).

Table-II

\begin{tabular}{lccc}
\hline & $\begin{array}{c}\text { Study group } \\
\text { Mean } \pm S D\end{array}$ & $\begin{array}{c}\text { Control group } \\
\text { Mean } \pm S D\end{array}$ & P-value \\
\hline Recurrence & & & \\
Post-operative & $6.762 \pm 7.15$ & $14.00 \pm 9.84$ & 0.003 \\
IPSS & & & \\
Post-operative & $18.19 \pm$ & $44.38 \pm$ & 0.001 \\
PVR & $30.530 \mathrm{ml}$ & $40.896 \mathrm{ml}$ & \\
Post-operative & $15.467 \pm$ & $13.871 \pm$ & 0.007 \\
Q-max & $4.5665 \mathrm{ml} / \mathrm{s}$ & $6.6735 \mathrm{ml} / \mathrm{s}$ & \\
\hline
\end{tabular}

\section{Discussion}

Posterior urethral injury is the most debilitating of all the injuries of urinary tract and an inappropriate management of it may lead to life long deleterious consequences regarding voiding, urinary continence \& potency. Due to this reason posterior urethral distraction defect has been a reconstructive dilemma for many years due to high incidence of recurrence as well as less than satisfactory outcomes.

To overcome these outcome limitations, several peroperative techniques were adopted, of all the techniques complete excision of scar tissues, fixation of mucosa with surrounding tissue and creation of a tension free anastomosis- are called "golden triad" contributing to a successful outcome.

In this context, the current study analyzed the outcome of anastomotic urethroplasty between two groups, as defined by mucosal fixation or without mucosal fixation. The mean age of the study group was $37( \pm 7.668)$ \& control group was $38.76( \pm 8.526)$ and there was no statistically significant difference in terms of age between the study \& control group. Morey et al, 1997, studied on patients with similar mean age of 35.5 years $^{6}$.

In the present study, the study group and the control group were statistically similar in terms of length of gap $(p=0.135)$ and the duration of symptom passed after the urethral injury $(p=0.332)$. This added an advantageous state to work on two groups those were almost statistically homogenous.

The failure rate was found significantly low $(p=0.043)$ in cases of anastomotic urethroplasty with mucosal fixation (study group) rather than in cases of anastomotic urethroplasty without mucosal fixation (control group). Koraitim \& Kamel. 2015 showed on univariate analysis that fixation of mucosa of the two urethral ends is one of four significant factors for a successful outcome. They showed $92 \%$ success rate after anastomotic urethroplasty with mucasal fixation $\& 67 \%$ success rate when anastomosis was done without mucosal fixation ${ }^{5}$. The present study also found similar type of success rate in mucosal fixation group $(85.71 \%)$ and without mucosal fixation group (57.14\%).

On comparing the post-operative IPSS between the study group and control group, there were increase in IPSS in control group than in study group and the increase is statistically significant $(p=0.003)$. Moreover there is significant $(p=0.001)$ increase in post operatie post void residual urine in control group than in study 
group. As a sequelae of these the post operative maximum urine flow rate is significantly higher $(p=0.007)$ in study group than in control group.

After reviewing the result of this recent study, it became evident that the success rate of anastomotic urethroplasty when done by mucosal fixation technique has been significantly increased. Though a multivariate analysis was not performed in this study. Because Koraitim et al, 2015 found mucosal fixation of the two urethral ends to be a significant factor on univariate analysis but on multivariate analysis only adequate exicision of scar tissue and lateral displacement of prostate were found to be significant factors for outcome ${ }^{5}$.

The present study showed a high failure rate after anastomotic urethroplasty without mucosal fixation. The cause of this may be due to performance of anastomotic urethroplasty by different surgeons of the department of urology, BSMMU. The other outcome variables - exicision of scar tisuue, lateral displacement of prostate, suture size and no. of suture were not analysed in this current study and a multivariate analysis was also not performed. The other complications of anastomotic urethroplasty - impotence and incontinence were not recorded in this study. The follow-up period was short which is a weak dimension of the study.

This present study was a prospective one and was done in between two almost homogenous groups. On the other hand, most of the previous studies were retrospective. Moreover, this type of study was not published in Bangladesh till to date.

So, a long term multicentric trial including other outcome variables is recommended to comment on the operative variables to be adopted during anastomotic urethroplasty which may have a huge impact on the success rate.

\section{References}

1. Kurt A, Mc Cammon, Jack M, Zuckerman, Gerald $\mathrm{H}$, Jordan. Surgery of the Penis and Urethra. In: Alan J. Wein, Louis R. Kavoussi, Alan W. Partin, Craig A. Peters, editors.Campbell-Walsh Urology. $11^{\text {th }}$ ed. Philadelphia: Elsevier;2016. p. 930.

2. Marshall FF, 1996, Operative Urology, WB Saunders Company, Philadelphia.

3. Mundy AR: Urethroplasty for posterior urethral strictures. Br J Urol 1996; 78: 243. 3.

4. Culty T, Boccon-Gibod L. Anastomotic urethroplasty for post traumatic urethral stricture: previous urethral manipulation has a negative impact on the final outcome. J Urol. 2007;177:13747.

5. Koraitim M.M.and Kamel M.I: Perineal repair of pelvic fracture urethral injury:in pursuit of a successful outcome. BJU Int 2015; 116,265-270.

6. Morey AF and McAninch JW: Reconstruction of posterior urethral disruption injuries: outcome of analysis in 82 patients. J Urol 1997; 157: 506. 5. 